\title{
Optimize education resource based on developing information system for deepening School- enterprise cooperation
}

\author{
Sun Lei \\ Department of information technology \\ College of Taishan \\ Taian, China
}

\author{
Jiang Huanwei \\ Department of information technology \\ College of Taishan \\ Taian, China
}

\begin{abstract}
This paper analyzes the necessary demand of information system under the background of deepening School-enterprise cooperation, and studies the present research situation of informatization in school enterprise cooperation, and sums up the characteristics of previous research. In combination with the school enterprise cooperation and quality evaluation system, the relevant evaluation dimensions of relevant information systems are put forward. In the proposed deepening school ente rprise cooperation, including pools by constructing policy pool, information pool, condition pool, project pool, culture pool,talent pool, teachers pool, project pool, curriculum pool, cultural integrated enterprise information communication platform, optimize the allocation of resources, in the common interests of both sides under the premise of realizing the integration of research, improve the quality of education.
\end{abstract}

Keywords -Informatization;Deepening School-enterprise cooperation;Optimize resource

\section{INTRODUCTION}

School-enterprise cooperation is a comprehensive way to open schools, with schools or enterprises as the nodes, which can form a global or regional school enterprise cooperation network, forming the sharing of resources between schools and enterprises. School enterprise deep cooperation [1], is relative to the shallow cooperation between school and enterprise, mainly refers to the cooperation between school and enterprise, not only "results" cooperation, but also "process" cooperation. Depth cooperation on the one hand, the chain of school enterprise cooperation is extended, on the other hand, the school enterprise cooperation will be expanded, and the number of contacts between the two sides will increase[2], and the interdependence will also increase, and the level of cooperation will naturally increase.

With the deepening of cooperation, will need to combine teaching and production, both sides support each other, mutual penetration, mutual involvement, complementary advantages, resource sharing, mutual interests, is the realization of higher vocational education and the modernization of enterprise management [3], promoting the development of productive forces, to speed up the enterprise's own talent education, the education and the sustainable development of production.

\section{INFORMATION SYSTEM IS NECESSARY FOR DEEP COOPERATION BETWEEN SCHOOL AND ENTERPRISE}

In the deepening of cooperation, how to enhance the quality of enterprise information sharing and optimizing the allocation of resources will restrict cooperation, so the cooperation of schools and enterprises in both schools need to have a good communication platform for [4], because the school needs to grasp the enterprise information and information technology research and development, staff training information, enterprise it is necessary to grasp the students of the school teachers bear the supply of information, information technology research and development and the reform of school education and cultural construction of information. The application of information technology innovation as the key basis of the reform and development of occupation education and strategic support ", with the combination of theoretical research and practice principle, to explore the effective way of information technology to support production and education, with the combination of engineering, school enterprise cooperation, internship, the formation of long-term mechanism of school enterprise cooperation and common education, promote the harmonious development of students' knowledge, skills and occupation accomplishment. Truly realize the "education informatization ten year development plan (2011-2020)" proposed "information technology to support the combination of production and education, school enterprise cooperation, the combination of engineering, post practice" [5] . 


\section{THE PRESENT STAGE OF THE SCHOOL ENTERPRISE COOPERATION IN THE INFORMATION SYSTEM RESEARCH}

In the school enterprise cooperation, the use of information platform has attracted the attention of many researchers. Cong and Wang Xiaomei believe that, in order to adapt to the current social and economic development, vocational schools and industry enterprises cooperation is one of the most effective methods. Information and communication technology (ICT) provides a variety of support occupation education activities and experience, such as abundant resources and e-learning courses, the occupation education occupation method and global information society in the integration of [6]; taking the construction of insurance production and research network of Zhejiang Financial College as an example, the use of network information construction technology cooperation to achieve the win-win result. In the view of humanism and informatization[7], has analyzed school enterprise cooperation based on "network space" [8]. Shao Rujun, member of Wang Dan to solve the problem caused by the decentralized regional group education, improve the degree of collectivization, that must build the sharing of teaching and scientific research management information technology platform, improve operation efficiency and reduce the operation cost of the group using the platform [9].

\section{DEEPEN THE SCHOOL ENTERPRISE COOPERATION, CONSTRUCT THE STRATEGY OF INFORMATION SYSTEM}

At present, most of the school enterprise cooperation in the higher vocational education is the one-way connection, and it is difficult to grasp the information of the schools and enterprises which have not formed cooperative relations. Many projects may be missed because of communication barriers. Now the school and enterprise cooperation is temporary, most of the stage, to solve the immediate problems, only need to implement the order training and build a base, internships and other matters, relevant personnel to communicate, purpose and point of single, double side school enterprise cooperation personnel is not much contact with each other, know less, can not continue to effectively carry out mutual cooperation, it is difficult to expand areas of cooperation and to explore and research the key issues in depth on post. In view of this situation, individual schools or companies are trying to build a platform for cooperation through the establishment of cooperative website, to strengthen the communication between the two sides, but because of the limited influence, attention is limited in this unit, other companies or schools rarely involved, failed to form the desired effect, so as to expand more units or projects to achieve the depth and breadth cooperation form platform is difficult. The construction of information system for enterprise [10] therefore deepen cooperation should be in double on the basis of mutual benefit, seek cooperation pilot functional requirements, comprehensive consideration of the school to achieve the purpose of the design is finished, so it can be expanded and can be extended to achieve social benefits.

School enterprise cooperation quality evaluation system of standards and contents, from three aspects of school conditions, educational process, educational effect, involving government policy, cooperative enterprises, teachers, funding, school training base in five dimensions including process conditions; professional construction, curriculum reform, teaching material construction, teaching part four process dimensions. Professional accomplishment and qualification certificate, employment, enterprise benefit, teaching and research result, social service and enterprise subsidy five dimensions[11]. Information system design services in the enterprise should meet the basic needs of deepening cooperation or meet the above quality evaluation standard, should from the point of coordination design, complete the integration of policies, personnel, teachers, curriculum, training projects focus frame.

School enterprise cooperation is a new mode of education in Colleges and universities, must closely around the fundamental task of "moral education" [12]. The cultivation of students in Colleges and universities is not only to cultivate excellent professional qualities, but also to cultivate socialist successors with high moral emotion quotient, a high outlook on life and a correct outlook on the world. Under the " $3+1$ " mode of undergraduate education in school enterprise cooperation, how does moral education run through school education and enterprise education? Need to do a good job of convergence, to record on their students' behavior through information technology, makes the enterprise through the detailed data records can be familiar with the students to carry out the work of moral education in a short time, do. Therefore, the cultivation and management of students' moral education is also an important consideration for deepening cooperation and informatization.

\section{DEEPEN THE SCHOOL ENTERPRISE COOPERATION, THE FORMATION OF INFORMATION SYSTEMS}

Based on previous research and practice, the author thinks that the development of school enterprise cooperation related information platform is conducive to deepening the cooperation to enhance the effect of educating people, we must first solve the problem of the construction and utilization of the enterprise resource pool, pool, pool a separating conditions of teachers, curriculum pool, pool, pool, pool, project occupation information pool, pool culture etc. the classification of resources as the basis of security cooperation from the enterprise resource pool. Considering the moral education requirements of college education, we should innovate the management means of school enterprise cooperation, construct the corresponding moral management module, and realize the process control and performance evaluation of school enterprise cooperation.

The information sharing module contains policy pools and information pools. The implementation of national policy sharing pool, cooperative education policies and regulations related to fundamental policy, focus on cooperation in the field of professional development, student employment trends, refer to the local or regional economic development policy oriented, combined with education related to long-term planning, to assist the cooperation department to make forward-looking planning. The information pool realizes the sharing of teaching plan and development plan. 
The hardware module contains the conditional pool and the project pool. The condition pool is land area, building area, facilities, equipment, fixed assets and so on. Project pool includes project preparation, project research, student training arrangement and so on.

Skill training module contains three parts: curriculum, teachers and talents. The course pool implements the curriculum arrangement, examination arrangement, practice arrangement, online course training and so on. Teacher pool to achieve classification records, professional division of the teacher files, external personnel registration. To achieve good records in the pool of Talent Training Institute, outstanding graduate school, potential recruitment, personnel exchange and other information.

The comprehensive quality module includes the cultural pool and the moral education management. Among them, the cultural pool mainly includes cooperative enterprises, enterprise culture and professional accomplishment training requirements, professional ethics education, school humanistic culture and so on. The moral education management records and receives the situation of moral education and daily performance from the aspects of daily behavior record, theme activity, comprehensive assessment, moral quality, honesty and social practice.

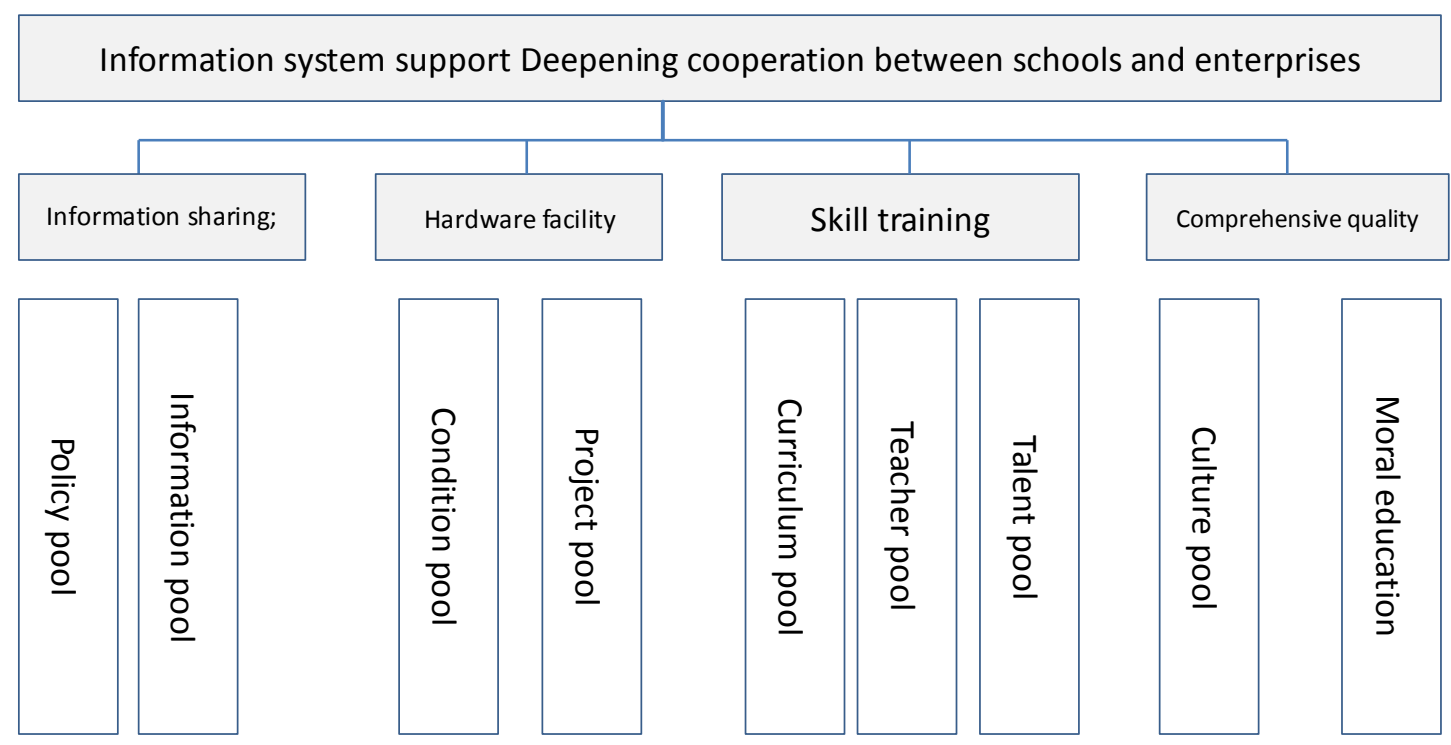

Figure 1. Information system support Deepening cooperation between schools and enterprises

\section{SUMMARY}

Comprehensive consideration of enterprise cooperation needs, combined with the existing evaluation methods, focusing on the basic requirements of college education, the basic module of information system services in the enterprise put forward to deepen cooperation, then the function of each module of the function, in order to enhance the integration advantages for enterprise to further deepen cooperation efforts, to provide the reference.

\section{REFERENCES}

[1] Baotao Jiang. Hongwei Zhang. Exploration of some problems restricting the deep cooperation between schools and enterprises [J]. science and technology information, 2012(23):315.

[2] [Zhenyin Hong. Study on Problems and thinking of higher occupation education of school enterprise cooperation [J]. higher educ ation research, 2010 (07):5863.

[3] Zhu Miao. Problems and Countermeasures of deep cooperation between schools and enterprises in Vocational Colleges [J]. succes s: education,.2012 (4):7-8.

[4] Jianshi Ding. Research on the deep cooperation between schools and enterprises based on the construction of community of interests. Heilongjiang higher education research, 2013, 31 (1): 69-71.

[5] Ming Zhang, Bing Fan. Study on the educational mechanism of school enterprise cooperation supported by educational informatization [J]. Journal of Jiangxi broadcast University, 2015 (1): 78-81.

[6] Sen Cong,Xiaomei Wang.A Perspective on Technical and Vocational Education and Training[J]. Advances in Computer Science and Engineering, 2012(141) : $67-75$.

[7] Jin Jiang, Pingjin Zhang. The construction of information network platform of school enterprise cooperation -- Taking Zhejiang Financial College insurance production and research network as an example of higher occupation education based on [J]. Higher Vocational Education (Journal of Tianjin Vocational Institute), 2011 (02): 38-41.

[8] Zhongjun Wang. From the perspective of enterprise informatization occupation on education cooperation, the combination of production and education of the ideological. [J] Education and profession.2013 (32): 171-172. 
[9] Rujun Shao, Dan Wang. Reflections on the collectivization of Vocational Education in the information age [J]. China information technology education, 2014(04):240.

[10] Liangming Li. Research on the construction of information platform for sharing school enterprise cooperation based on synergy theory [J]. modern industrial economics and information technology, 2015, (11): 90 - 91

[11] Xiaojuan Li. Construction of quality evaluation system of deep cooperation between school and enterprise in Vocational Education [J]. Trade Union Forum, 2013 (19): 5.

[12] Information on http://news.ifeng.com/a/20161209/50388111_0.shtml 